\title{
Crystal data for high-pressure phases of silicon
}

\author{
Jing Zhu Hu, Larry D. Merkle, ${ }^{*}$ Carmen S. Menoni, and Ian L. Spain \\ Department of Physics, Colorado State University, Fort Collins, Colorado 80523
}

(Received 31 March 1986)

\begin{abstract}
$\mathrm{X}$-ray-diffraction data have been obtained on $\mathrm{Si}$ in a diamond anvil cell to pressures of $\sim 50 \mathrm{GPa}$. Crystallographic data are presented in phase I (cubic, diamond), II (tetragonal, $\beta$-Sn), V (simple hexagonal), VII (hexagonal close-packed), and the metastable phase III [body-centered-cubic (BC8)] and on the coexistence of the phases. Comparison is made between these data and the predictions of $a b$ initio calculations for these structures and their equations of state.
\end{abstract}

\section{INTRODUCTION}

There have been many studies of the high-pressure phases of Si since the pioneering work of Minomura and Drickamer. $^{1}$ These authors inferred a phase transition from a drop of several orders of magnitude in the resistivity. Since that time the transition has been studied using electrical resistance, ${ }^{2-7} \mathrm{x}$-ray diffraction (in situ ${ }^{8-12}$ and on quenched specimens ${ }^{2,13}$ ), and optical properties. $^{14-16}$ Shock studies have also been carried out. ${ }^{17-19}$ These references are restricted to work on crystalline material and do not include extensive work in amorphous samples.

Early $x$-ray-diffraction studies ${ }^{6,8,9}$ reported only the cubic (diamond) to body-centered-tetragonal ( $\beta$-Sn) transition, which occurs at $\sim 11 \mathrm{GPa}$, and for which there have been several theoretical studies. ${ }^{20-28}$ More recent experiments ${ }^{10-12}$ were partly motivated by the prediction ${ }^{24}$ of a hexagonal-close-packed phase above $40 \mathrm{GPa}$, which has been observed by us ${ }^{12}$ and other workers. ${ }^{10}$ However, an intermediate primitive hexagonal phase was also found $^{10,11}$ on compression of the $\beta$-Sn phase above about $14 \mathrm{GPa}$. This phase has since been studied theoretically and confirmed to be a thermodynamically stable phase between $\sim 14$ and $43 \mathrm{GPa}{ }^{27,28}$

The labeling of the high-pressure phases is given in Table I and is consistent for the lower-pressure phases with Cannon's review of the phases of the elements. ${ }^{29}$ Phase III is found on quenching the $\beta$-Sn phase at room temperature and is discussed in this paper. Since phase IV is assigned to a similar quenched phase to III, $^{29}$ the primitive hexagonal phase is designated $V$. The hexagonal-close-packed phase is designated VII since Olijnyk et al. ${ }^{10}$ tentatively identified another highpressure phase immediately before the hcp phase.

The observation of phases V and VII has been reported briefly by us in previous publications. ${ }^{11,12}$ The purpose of the present paper is to report further details of the principal transitions occurring at room temperatures on increase and decrease of pressure up to $\sim 50 \mathrm{GPa}$ for crystalline Si.

\section{EXPERIMENTAL DETAILS}

Experimental details of x-ray-diffraction procedures using both conventional and synchrotron sources have been discussed elsewhere. ${ }^{30}$ In order to study the influence of nonhydrostatic stress on the transition, selected experiments were carried out with the sample compressed in the gasket without a fluid, and also with different compressing media, including one on $\mathrm{Si}$ compressed in solid argon, which should remain quasihydrostatic to $\sim 50 \mathrm{GPa}^{31}$ The diamond cell was modified for this purpose, so that four screws could be located in the body of the cell, holding the piston back against the Belleville springs. Argon gas was fed to the sample area as the diamond cell was slowly cooled to $77 \mathrm{~K}$. While still at $77 \mathrm{~K}$, the four screws were retracted so that the springs pushed the piston forward, trapping solid argon in the sample cavity. Samples were in the form of lightly compacted disks of sufficiently small thickness that the diamond anvils could not compress them directly, as suggested by Werner et al. ${ }^{9}$

TABLE I. Designation of high-pressure phases stated in this paper (Refs. 29, 10, and 11).

\begin{tabular}{clc}
\hline \hline Designation & \multicolumn{1}{c}{ Structure } & $\begin{array}{c}\text { Pressure } \\
\text { region } \\
(\mathrm{GPa})\end{array}$ \\
\hline I & Cubic (diamond) & $0 \rightarrow \sim 11$ \\
II & Body-centered tetragonal $(\beta$-Sn) & $\sim 11 \rightarrow 15$ \\
III & Body-centered cubic & $\sim 10 \rightarrow 0$ \\
V & Primitive hexagonal & $\sim 14 \rightarrow 40$ \\
VII & Hexagonal close-packed & $\sim 40$ \\
\hline \hline
\end{tabular}

${ }^{\mathrm{a} O f t e n}$ referred to as $\mathrm{BC} 8$ phase. 


\section{EXPERIMENTAL RESULTS}

Experimental results will be discussed taking each phase and transition in turn.

\section{A. Phase I (cubic, diamond)}

The present experimental points are in good agreement with the $x$-ray-diffraction data of Senoo et al. ${ }^{32}$ to $8 \mathrm{GPa}$, but lie somewhat below the $V(P)$ curve of Vaidya and Kennedy ${ }^{33}$ and significantly below the data of Bridgman, after revision of the data to account for changes in the pressure scale. $^{34}$ The discrepancy with the more modern piston-cylinder results of Vaidya and Kennedy is not understood. The best experimental values of the bulk modulus $B_{0}$ and its pressure derivative $B_{0}^{\prime}$ at zero pressure are based on elastic constant data $\left(B_{0}=97.88 \mathrm{GPa}\right.$; $\left.B_{0}^{\prime}=4.24\right){ }^{35}$ The present data and those of Senoo et al. ${ }^{32}$ are consistent with the Murnaghan equation using these values, within experimental error.

Soma ${ }^{36}$ calculated the $V(P)$ curve for $\mathrm{Si}(\mathrm{I})$ using a pseudopotential approach. The present experimental data lie just above the range of his calculated $V(P)$ values. A more recent calculation of Yin and Cohen ${ }^{23}$ gives $B_{0}=98$ $\mathrm{GPa}$, in excellent agreement with the present results.

\section{B. I $\rightarrow$ II transition and phase II}

Experimental results for the $\mathrm{I} \rightarrow \mathrm{II}$ transition and phase II are given in Table II. A strong case can be made for accepting these pressures $(11.3-12.5 \mathrm{GPa}$ onset and completion) as representative of hydrostatic conditions. Firstly, the samples were in the form of lightly compacted disks of thickness less than the minimum anvil separation so that anvil contact could not produce shear stresses in the samples. Secondly, essentially identical results were obtained using 4:1 methanol:ethanol solution, and solid argon. In both cases, ruby fluorescence peaks were well defined. Excellent agreement is noted for $P_{t}$ with the optical experiment of Welber et al. ${ }^{14}$ using a 4:1 alcohol mixture.

The transition pressure is lowered by the application of nonhydrostatic stress. In one experiment, where the sample was held within a gasket, but without a pressurizing medium, a transition pressure onset of $\sim 8.5 \mathrm{GPa}$ was recorded. This is in good accord with the results of Gupta and Ruoff ${ }^{7}$ who found an initial drop in resistance at $\sim 8 \mathrm{GPa}$ when uniaxial stress was applied along the [111] direction.

Reasonable agreement for $\boldsymbol{P}_{t}$ and lattice parameters is obtained with Jamieson's early experiment ${ }^{8}$ within experimental error, but the present results are more precise. Olijnyk et al. ${ }^{10}$ also reported results on the $\mathrm{I} \rightarrow \mathrm{II}$ transi-

TABLE II. Comparison of experimental and theoretical data for phases I and II and the I $\rightarrow$ II transition.

\begin{tabular}{|c|c|c|c|}
\hline Parameter & $\begin{array}{c}\text { Present } \\
\text { experiment }\end{array}$ & $\begin{array}{c}\text { Other } \\
\text { experiments }\end{array}$ & Theory \\
\hline $\begin{array}{l}\text { Cubic cell parameter } a(\AA) \\
\text { phase } I, P=0\end{array}$ & & $5.435^{\mathrm{a}}$ & \\
\hline$\underset{I \rightarrow I I}{\text { Transition pressure } P_{t}(\mathrm{GPa})}$ & $\begin{array}{rr}\text { Onset: } & 11.3 \pm 0.2 \\
\text { Completion: } & 12.5 \pm 0.2\end{array}$ & See text & $\begin{array}{l}14.8,^{b} 12.4-15.2,^{c} \\
9.9,^{d} 7.0,^{\mathrm{e}} 9.3^{\mathrm{f}}\end{array}$ \\
\hline $\begin{array}{l}\text { Lattice parameter } a(\AA) \\
\qquad P=P_{t} \text {, phase I }\end{array}$ & $\begin{array}{l}5.268 \pm 0.010 \\
(\text { at } 11.3 \mathrm{GPa})\end{array}$ & $\begin{array}{l}5.282^{\mathrm{g}} \\
(12 \mathrm{GPa})\end{array}$ & $\begin{array}{l}5.214-5.226^{\mathrm{c}} \\
5.301^{\mathrm{d}}\end{array}$ \\
\hline \multirow[t]{2}{*}{$\left(V / V_{0}\right)\left(P_{t}\right)$, phase I } & Onset: $\quad 0.911 \pm 0.003$ & $0.918^{8}$ & $0.883-0.889^{c}$ \\
\hline & Completion: $\quad 0.906 \pm 0.003$ & at $12 \mathrm{GPa}$ & $0.928^{d}$ \\
\hline $\begin{array}{l}\text { Lattice parameters } a, c(\AA) \\
\text { phase II }\left(P=P_{t}\right)\end{array}$ & $\begin{array}{r}a=4.69 \pm 0.006 \\
c=2.578 \pm 0.005\end{array}$ & & $\begin{array}{l}a=4.705-4.720, c=2.499-2.502^{\mathrm{d}} \\
a=4.691, c=2.463^{\mathrm{e}} \\
a=4.715, \quad c=2.593^{\mathrm{e}} \\
a=4.565, \quad c=2.515^{\mathrm{f}}\end{array}$ \\
\hline$c / a$ ratio & $0.550 \pm 0.002$ & $0.554^{\mathrm{B}}$ & $\begin{array}{l}0.530,^{c}(0.55 \pm 0.027)^{d} \\
0.525,^{e} 0.551^{f}\end{array}$ \\
\hline$\left(V / V_{0}\right)^{\mathrm{II}}\left(P_{t}\right)$ & $0.706 \pm 0.003$ & $0.709^{8}$ & $\begin{array}{l}0.696-0.700,^{\mathrm{c}} 0.718^{\mathrm{d}} \\
0.707,,^{\mathrm{e}} 0.707^{\mathrm{d}}\end{array}$ \\
\hline$\frac{\left(V^{\mathrm{I}}-V^{\mathrm{II}}\right)\left(P_{t}\right)}{V^{\mathrm{I}}\left(P_{t}\right)}$ & $0.204 \pm 0.004$ & $0.209^{8}$ & $0.213-0.217,^{\mathrm{c}} 0.26^{\mathrm{d}}$ \\
\hline
\end{tabular}

${ }^{2}$ Reference 29.

beference 20 .

'Reference 21.

${ }^{\mathrm{d}}$ Reference 23.

Reference 27.

Reference 28.

${ }^{8}$ Reference 8 . 
TABLE III. Experimental parameters for phase $V$ and $I I \rightarrow V$ transitions and comparison with theory.

\begin{tabular}{|c|c|c|c|}
\hline Parameter & $\begin{array}{c}\text { Present } \\
\text { experiment }\end{array}$ & $\begin{array}{l}\text { Olijnyk et } a l^{\mathrm{a}} \\
\text { experiment }\end{array}$ & Theory \\
\hline$\underset{\mathrm{II} \rightarrow \mathrm{V}}{\text { Transition pressure } P_{t}(\mathrm{GPa})}$ & $\begin{array}{rr}\text { Onset: } & 13.2 \pm 0.2 \\
\text { Completion: } & 16.4 \pm 0.5\end{array}$ & $\sim 16$ & $14.3,^{b} 12.0^{c}$ \\
\hline $\begin{array}{l}\text { Lattice parameters } a, c(\AA) \\
\text { phase } V(\sim 16 \mathrm{GPa})\end{array}$ & $\begin{array}{l}a=2.551 \pm 0.006 \\
c=2.387 \pm 0.007\end{array}$ & $\begin{array}{l}2.527 \\
2.373\end{array}$ & $\begin{array}{l}a=2.400, c=2.297^{\mathrm{b}} \\
a=2.561, c=2.446^{\mathrm{c}}(\text { Values at } 12 \mathrm{GPa})\end{array}$ \\
\hline$c / a(P \sim 16 \mathrm{GPa})$ & $0.936 \pm 0.005$ & 0.937 & $0.957,,^{b} 0.955^{c}($ Values at $12 \mathrm{GPa})$ \\
\hline $\begin{array}{c}\text { Volume } V_{t}\left(\AA^{3} / \text { at. }\right) \\
\text { phase } V \quad\left(P=P_{t} \sim 16 \mathrm{GPa}\right)\end{array}$ & $13.45 \pm 0.10$ & 13.12 & $13.23,^{b} 13.5^{c}$ \\
\hline $\begin{array}{l}\text { Bulk modulus (GPa) } \\
\text { phase } V\end{array}$ & $310 \pm 30$ & & \\
\hline
\end{tabular}

${ }^{a}$ Reference 10.

${ }^{\mathrm{b}}$ Reference 27.

${ }^{\mathrm{C}}$ Reference 28 .

tion, reporting an onset of $8.8 \mathrm{GPa}$, indicative of nonhydrostatic conditions. These authors gave no details of lattice parameters.

A comparison between various experimental and theoretical parameters is included in Table III. Most interesting is the comparison with Yin and Cohen ${ }^{23}$ and Needs and Martin ${ }^{27}$ who used $a b$ initio band-structure calculations to generate the total energy of the crystal as a function of volume. The values of the lattice parameters are close to the experimental values, but both groups find a lower transition pressure than the experimental values. This is discussed further in Sec. IV.

Jamieson $^{8}$ observed extra lines $(d=2.613$, and $1.713 \AA$ ) in his X-ray-diffraction record of phase II. The estimated pressure for his experiment with phase II was $16 \mathrm{GPa}$, but this pressure probably corresponds to $\lesssim 13 \mathrm{GPa}$ using the ruby fluorescence scale, since at $16 \mathrm{GPa}$, phase $\mathrm{V}$ should predominate. The persistence of some of the diffraction lines in Jamieson's experiment after release of pressure indicates that phases II and III were present in his sample volume. No trace of phase III was found in the present experiments while pressure was increased, or even held at $13 \mathrm{GPa}$ for several days. This implies that a fairly large pressure gradient was present across Jamieson's Si sample, and that part of the sample (probably those parts furthest from the axis of the anvils) initially converted to phase II on increase of load, then converted to phase III as the pressure locally fell below $\sim 8.5 \mathrm{GPa}$ due to sample flow. This result is consistent with Jamieson's setup ${ }^{37}$ where $x$ rays pass parallel to the anvil faces since diffraction information is obtained from crystal planes that are subject to a large pressure gradient.

\section{II-V transition and phase $\mathrm{V}$}

The onset of the transition from $\mathrm{Si}(\mathrm{II})$ to $\mathrm{Si}(\mathrm{V})$ was observed at $13.2 \pm 0.2 \mathrm{GPa}$ (Ref. 11). The crystal structure of $\mathrm{Si}(\mathrm{V})$ was identified as simple hexagonal, with lattiçe parameters $a=(2.551 \pm 0.006) \AA, c=(2.387 \pm 0.007) \AA$. Data for phase $\mathrm{V}$ and II-V transition are listed in Table III.

Olijnyk et al. ${ }^{10}$ also concluded that the structure of $\mathrm{Si}$ in this region was primitive hexagonal. Small differences are to be noted between the two experiments. Firstly, the relative volumes found by us up to $25 \mathrm{GPa}$ are slightly higher than those of Olijnyk et al. ${ }^{10}$ while reasonable agreement is recorded for phase II. The origin of this discrepancy is not clear. The absolute error in the values of lattice parameters $a$ and $c$ for phase $V$ were estimated to be $\pm 0.006 \AA$, so that $\Delta V / V_{0}$ is calculated to a precision of $\pm 0.3 \%$. Differences in volume between the present results and those of Olijnyk et al. ${ }^{10}$ amount to $\geq 1 \%$ in this pressure region.

Figure 1, taken from Needs and Martin, ${ }^{27}$ illustrates the structure of $\mathrm{Si}(\mathrm{II})$ and $\mathrm{Si}(\mathrm{V})$, and the calculated atomic displacements needed to affect the transition. Note that in the body-centered-tetragonal structure, the coordination

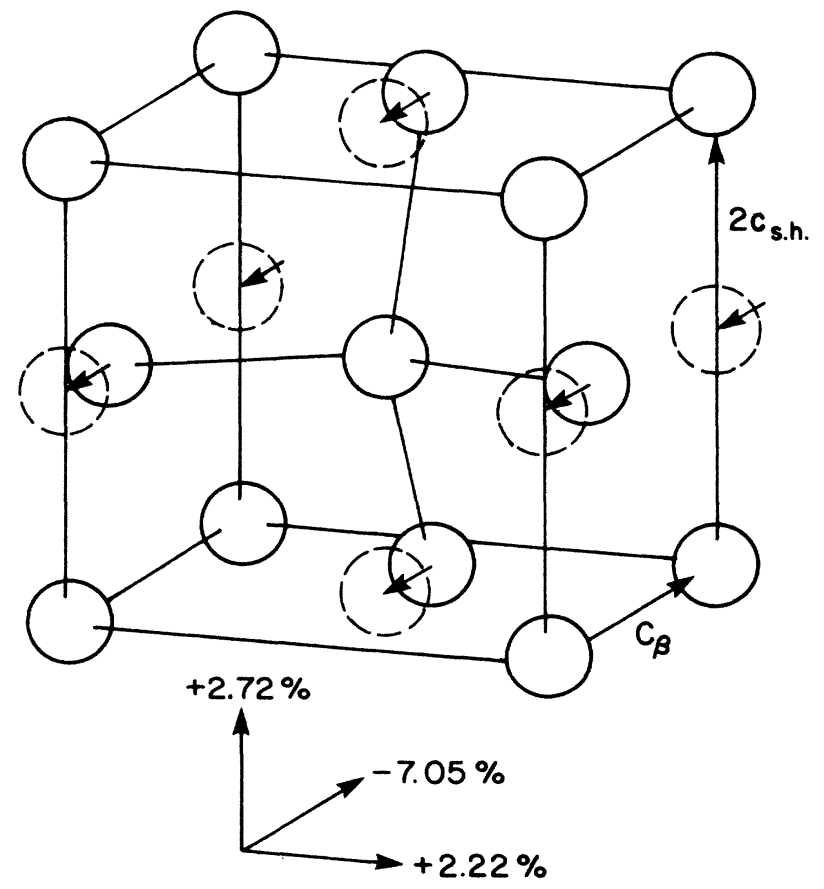

FIG. 1. A sketch of the unit cells for $\mathrm{Si}(\mathrm{II})$ and $\mathrm{Si}(\mathrm{V})$, reproduced with permission from Needs and Martin (Ref. 27). The arrowed percentages indicate the calculated lattice distortions for $\mathrm{II} \rightarrow \mathrm{V}$. 
TABLE IV. Experimental and theoretical data for phase VII (hcp) (Si).

\begin{tabular}{|c|c|c|c|}
\hline Parameter & $\begin{array}{c}\text { Present } \\
\text { experiment }\end{array}$ & $\begin{array}{l}\text { Experiment of } \\
\text { Olijnyk et al. }{ }^{\mathrm{a}}\end{array}$ & Theory \\
\hline Transition pressure $P_{t}(\mathrm{GPa})$ & $\sim 36-42$ & $\sim 42$ & $\begin{array}{l}41^{b, c} \\
41^{b}\end{array}$ \\
\hline Lattice parameters ${ }^{\mathrm{d}} a, c(\AA)$ & $\begin{array}{c}a=2.524 \pm 0.009 \\
c=4.142 \pm 0.05\end{array}$ & $\begin{array}{l}2.444 \\
4.152\end{array}$ & $\begin{array}{l}2.469^{\mathrm{e}} \\
4.185^{\mathrm{e}}\end{array}$ \\
\hline$c / a^{\mathrm{f}}$ & $1.64 \pm 0.02$ & 1.70 & $\begin{array}{l}1.67^{\mathrm{c}} \\
1.695^{\mathrm{e}}\end{array}$ \\
\hline $\begin{array}{l}V^{\mathrm{VII}}(\AA)^{3} / \text { at. }^{\mathrm{d}} \\
V^{\mathrm{V}}(\AA)^{3} / \text { at. }^{\mathrm{d}}\end{array}$ & $\begin{array}{l}11.4 \pm 0.2 \\
12.3 \pm 0.2\end{array}$ & 10.7 & $\begin{array}{l}11.02^{\mathrm{e}} \\
11.96^{\mathrm{e}}\end{array}$ \\
\hline
\end{tabular}

${ }^{\text {a Reference } 10 .}$

${ }^{b}$ These authors calculate the transition pressure for $\beta-\mathrm{Sn} \rightarrow \mathrm{hcp}$.

${ }^{\mathrm{c}}$ Reference 24.

dAt 41-42 GPa.

${ }^{\text {e}}$ Reference 28.

${ }^{f}$ Based on extrapolation of data.

can be viewed as sixfold, since at $12 \mathrm{GPa}$ there are four nearest neighbors at a distance of $2.43 \AA$ and two nextnearest neighbors at a slightly greater distance $c=2.58 \AA$. Similarly, the hexagonal structure can be viewed as eightfold with six atoms on the basal plane and two atoms at a slightly shorter distance $c$ (Table III). Thus the coordination number increases from $4 \rightarrow 6 \rightarrow 8 \rightarrow 12$ when the pressure is increased.

An increasing trend was found in the $c / a$ ratio of phase $\mathrm{V}$ with pressure. Data are plotted in Fig. 2 as $c / a$ versus atomic volume to compare directly with the calculation of Needs and Martin ${ }^{27}$ and Chang and Cohen, ${ }^{28}$ and with the data of Olijnyk et al. ${ }^{10}$ The trend is similar, but the experimental values lie somewhat lower than the theoretical.

\section{Phase VII and the $\mathrm{V} \rightarrow$ VII transition}

Data for phase VII (Table IV) indicate differences between the present data and those of Olijnyk et al. ${ }^{10}$ The atomic volumes differ by $\sim 6 \%$, most of this difference being accounted for in the lattice parameter $a$. The

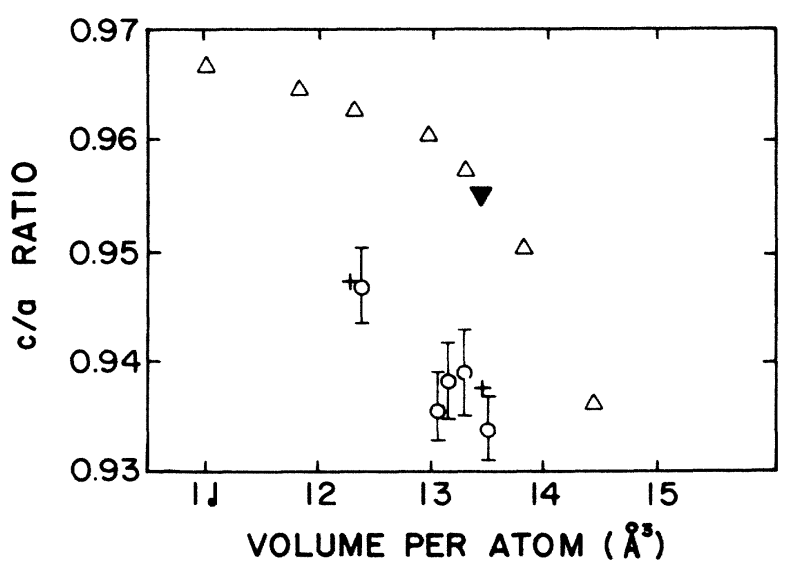

FIG. 2. The $c / a$ ratio for phase $\mathrm{V}$ as a function of atomic volume. $\triangle$, theory (Ref. 27 ); $\nabla$, theory (Ref. 28 ); + , experiment (Ref. 11); $\bigcirc$, present experiment with error bar indicated. reasons for these discrepancies are not known.

The transformation from the primitive hexagonal to hexagonal-close-packed structure can be accomplished by sliding each plane of atoms with respect to the next. In the process, the $a$ parameter does not change appreciably. [Extrapolated to $\sim 42 \mathrm{GPa}, a_{\mathrm{V}} \sim 2.46 \AA$, compared to $a_{\mathrm{VII}}=2.524 \AA$, so that a slight $(\sim 2 \%)$ expansion occurs.] The $c$ parameter decreases by $\sim 10 \%$. It is to be expected that such a large shear would lead to high densities of dislocations and planar defects in the two-phase region, accounting for the diffuse background observed between $\sim 36.5$ and $42 \mathrm{GPa}$. Olijnyk et al. ${ }^{10}$ concluded that a new phase (VI) exists in this region. Their notation for phases is followed in this paper to avoid confusion, but no evidence is presented in this paper for a new phase, nor is evidence presented against its existence.

\section{E. V $\rightarrow$ II and II $\rightarrow$ III transitions on decompression}

Experiments confirmed the sequence $\mathrm{V}(14.5 \mathrm{GPa})$

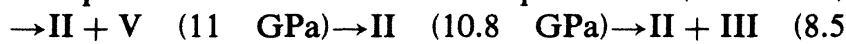
GPa) $\rightarrow$ III for stepwise decompression over a period of days. Table $\mathrm{V}$ lists the lattice parameters obtained in the present work for BC 8 phase (III), which is metastable at atmospheric pressure. ${ }^{2,13}$ The $\mathrm{x}$-ray-diffraction lines for III were broad, indicating a strained lattice.

\section{DISCUSSION}

This paper presents data for phases of Si which can be compared directly with $a b$ initio calculations. ${ }^{22-28}$ It is gratifying to note the good overall agreement between theory and experiment, and the ability of this theory to predict new phases.

$X$-ray data have been presented for the $\mathrm{Si}(\mathrm{I}) \rightarrow \mathrm{Si}(\mathrm{II})$ transition under close-to-hydrostatic conditions, and the effects of shear stresses have been examined. It is important to point out that comparison of experimental and theoretical transition pressures must be made with caution. Firstly, the theoretical results are obtained for $T=0$ K. Secondly, experimental transition pressures are not to be equated with (thermodynamic) equilibrium pressure, 
TABLE V. Data for phase III and V $\rightarrow$ II and II $\rightarrow$ III transitions or decrease of pressure.

\begin{tabular}{lcc}
\hline \multicolumn{1}{c}{ Parameter } & Present work & Other work \\
\hline$P_{t}(\mathrm{~V} \rightarrow \mathrm{II})(\mathrm{GPa})$ & $14.5-11$ \\
$P_{t}(\mathrm{II}-\mathrm{III})(\mathrm{GPa})$ & (phases $\mathrm{V}+$ II present) & $10.8-8.5$ \\
& (phases II + III present) & \\
Lattice parameter $(\AA)$ phase III & $6.405 \pm 0.005$ & \\
at $P_{t}(10 \mathrm{GPa})$ & $6.62 \pm 0.01$ & $6.636 \pm 0.005^{\mathrm{a}}$ \\
Lattice parameter $(\AA)$ phase III & & $6.67^{\mathrm{b}}$ \\
at $P=0$ & $6.66 \pm 0.03$ & $96^{\mathrm{b}}$ \\
Bulk modulus $(\mathrm{GPa})$ & \\
\hline \hline
\end{tabular}

${ }^{\mathrm{a}}$ Reference 13.

${ }^{\text {b}}$ Reference 26.

because kinetic factors are involved. If a complete hysteresis loop $(\mathrm{I} \rightarrow \mathrm{II} \rightarrow \mathrm{I})$ could be obtained, an estimate for the equilibrium pressure could be made. However, this is not possible for Si since the metastable phase III is produced on release of pressure. The only III-V compound on which a complete hysteresis loop has been obtained is InAs using $\mathrm{x}$-ray-diffraction data. ${ }^{38}$ From these data it is reasonable to conclude that transition pressures on increase of pressure may be overestimated by $2 \mathrm{GPa}$ or more. For Si the equilibrium transition pressure will be less than or equal to the onset pressure under hydrostatic conditions. No quantitative statement can be made relating the equilibrium pressure to the onset pressures obtained experimentally with either hydrostatic pressure, or with shear stresses present.

It is interesting to inquire whether phase III is a thermodynamically stable phase between phases I and II. If so, the fact that III is not observed on increase of pressure would be due to kinetic factors, as would the persistence of phase III to room pressure. However, Yin ${ }^{26}$ has calculated that phase III for Si is indeed metastable over the whole pressure range. His models permitted atoms to be shifted in various directions, indicating that phase III of $\mathrm{Si}$ is formed metastably from II on decrease of pressure because it is easier for atoms to move in the direction towards Si III, rather than towards the thermodynamically stable structure I.

The present work has been carried out with higher precision and accuracy (see Ref. 30 for a discussion) than the earlier work of Jamieson, ${ }^{8}$ whose values for volume changes at the transition were quoted by Van Vechten. ${ }^{20}$ Van Vechten used the volume-ratio $\left[V^{\mathrm{I}}\left(P_{t}\right)\right.$ $\left.-V^{\mathrm{II}}\left(P_{t}\right)\right] / V^{\mathrm{I}}\left(P_{t}\right)=0.209$ for $\mathrm{Ge}, \mathrm{Si}$, and $\mathrm{Sn}$ as a cornerstone of his calculation for the transition pressures of the group-IV elements and III-V compounds. This work was important, in that it stimulated many high-pressure studies of these materials, including the present one. However, the present data (see also Ref. 38 for similar data on III-V compounds) do not support his scaling relationship for the volume changes. The new $a b$ initio calculations of $\mathrm{Si}$ and $\mathrm{Ge}$ (Refs. 22-28) indicate that high-pressure behavior can be predicted accurately, and it is hoped that such work will be extended to III-V, II-VI, and other compounds.

\section{ACKNOWLEDGMENTS}

Thanks are due to NASA, Ames Laboratory for a grant supporting this work (NAG2-157). Professor W. A. Bassett and Professor A. L. Ruoff kindly lent equipment for experiments at the Cornell High-Energy Synchrotron Source (CHESS), and CHESS personnel gave much appreciated assistance. The help of Donald Trock at Colorado State University was invaluable. Dr. Richard M. Needs and Professor Marvin L. Cohen kindly sent copies of their work before publication, for which we are grateful. Thanks are also due to Dr. H. Olijnyk for communications regarding his work.
*Present address: Department of Physics, University of Arkansas, Fayetteville, Arkansas 72701.

1S. Minomura and H. G. Drickamer, J. Phys. Chem. Solids 23, 451 (1962).

${ }^{2}$ R. H. Wentorf and J. S. Kasper, Science 139, 338 (1963).

${ }^{3}$ F. J. Bundy, J. Phys. Chem. Solids 41, 3809 (1964).

4J. Wittig, Phys. Lett. 17, 187 (1965).

5 J. Wittig, Z. Phys. 195, 215 (1966).

${ }^{6}$ T. I. Dyuzheva, S. S. Kabalkina, and V. P. Novichkov, Zh. Eksp. Teor. Fiz. 74, 1784 (1978) [Sov. Phys.-JETP 47, 931
(1978)].

${ }^{7}$ M. C. Gupta and A. L. Ruoff, J. Appl. Phys. 51, 1072 (1980).

8 J. C. Jamieson, Science 139, 762 (1963).

${ }^{9}$ A. Werner, J. A. Sanjurjo, and M. Cardona, Solid State Commun. 44, 155 (1982).

${ }^{10}$ H. Olijnyk, S. K. Sikka, and W. B. Holzapfel, Phys. Lett. 103A (1984).

${ }^{11}$ J. Z. Hu and I. L. Spain, Solid State Commun. 51, 263 (1984).

12I. L. Spain, D. R. Black, L. D. Merkle, J. Z. Hu, and C. S. Menoni, High Temp.-High Pressures 16, 507 (1984). 
13J. S. Kasper and S. M. Richards, Acta Crystallogr. 77, 752 (1964).

${ }^{14}$ B. Welber, C. K. Kim, M. Cardona, and S. Rodriguez, Solid State Commun. 17, 1021 (1975).

${ }^{15}$ G. J. Piermarini and S. Block, Rev. Sci. Instrum. 46, 973 (1975).

16B. Weinstein, G. Piermarini, Phys. Rev. B 12, 1171 (1975).

${ }^{17}$ L. V. Al'tshuler, Usp. Fiz. Nauk 85, 197 (1965) [Sov. Phys.Usp. 8, 52 (1965)].

${ }^{18}$ M. N. Pavlovskii Fiz. Tverd. Tela (Leningrad) 9, 3192 (1968) [Sov. Phys.-Solid State 9, 2514 (1968)].

${ }^{19}$ W. H. Gust and E. B. Royce, J. Appl. Phys. 42, 1897 (1971).

20J. A. Van Vechten, Phys. Rev. B 7, 1479 (1973).

${ }^{21}$ T. Soma, Phys. Status Solidi B 92, K 51 (1979).

${ }^{22}$ M. T. Yin and M. L. Cohen, Phys. Rev. Lett. 45, 1004 (1980).

${ }^{23}$ M. T. Yin and M. L. Cohen, Phys. Rev. B 26, 5668 (1982).

${ }^{24}$ A. K. McMahan and J. A. Moriarty, Phys. Rev. B 27, 3235 (1983).

${ }^{25}$ R. Biswas and M. Kertesz, Phys. Rev. B 29, 1791 (1984).

${ }^{26}$ M. T. Yin, Phys. Rev. B 30, 1773 (1984).

${ }^{27}$ R. J. Needs and R. M. Martin, Phys. Rev. B 30, 5390 (1984).

${ }^{28}$ K. J. Chang and M. L. Cohen, Phys. Rev. B 31, 7819 (1985).
29J. F. Cannon, J. Phys. Chem. Ref. Data 3, 781 (1974).

${ }^{30}$ I. L. Spain, D. R. Black, L. D. Merkle, J. Z. Hu, and C. S. Menoni, High Temp.-High Pressures 16, 507 (1984).

${ }^{31}$ L. W. Finger, R. M. Hazen, G. Zou, H. K. Mao, and P. M. Bell, Appl. Phys. Lett. 39, 892 (1981).

${ }^{32}$ M. Senoo, H. Mii, I. Fujishiro, and T. Fujikawa, Jpn. J. Appl. Phys. 15, 871 (1976)

${ }^{33}$ S. N. Vaidya and E. C. Kennedy, J. Phys. Chem. Solids 33, 1377 (1972).

${ }^{34}$ P. W. Bridgman, Proc. Am. Acad. Arts Sci. 76, 55 (1948). [These data have been revised to take into account changes in pressure scales, by R. N. Keeler, American Institute of Physics Handbook, 3rd ed., edited by D. E. Gray (McGraw-Hill, New York, 1972), pp. 4-41.]

${ }^{35}$ Crystal and Solid State Physics, Vol. I of Landolt-Börnstein, Numerical and Functional Relationships in Science and Technology (Springer-Verlag, Berlin, 1966).

${ }^{36}$ T. Soma, Phys. Status Solidi B 88, K69 (1978).

37J. C. Jamieson and A. W. Lawson, J. Appl. Phys. 33, 776 (1962).

${ }^{38}$ I. L. Spain, J. Z. Hu, C. S. Menoni, and D. Black, J. Phys. (Paris), Colloq. 45, C8-407 (1984). 